\title{
Gastric Emptying in Migraine: A Comparison With Functional Dyspepsia
}

\author{
Yeon Hwa Yu, ${ }^{1}$ Yunju Jo, ${ }^{2 *}$ Jun Young Jung, ${ }^{2}$ Byung Kun $\mathrm{Kim}^{3}$ and Ju Won Seok ${ }^{4}$ \\ ${ }^{1}$ Department of Internal Medicine, Hanyang University College of Medicine, Guri, Gyeonggi-do, Korea; ${ }^{2}$ Department of Internal Medicine and \\ ${ }^{3}$ Neurology, Eulji General Hospital, Eulji University College of Medicine, Seoul, Korea; and ${ }^{4}$ Department of Nuclear Medicine, College of \\ Medicine, Chung-Ang University, Seoul, Korea
}

\begin{abstract}
Background/Aims
Gastric stasis in migraineurs remains controversial. The aim of this study is to investigate gastric emptying (GE) time, and any associations between GE parameters and dyspeptic symptoms among patients with functional dyspepsia (FD) and migraine without any gastrointestinal symptoms during the interictal period.
\end{abstract}

\section{Methods}

We enrolled 27 migraine patients, 32 FD patients and 12 healthy people as controls, and performed GE scintigraphy as gastric function test. Gastrointestinal symptoms were evaluated in the FD and migraine.

\section{Results}

The age-adjusted mean gastric half-emptying time in FD (125.51 \pm 52.55 minutes) patients was longer than in migraineurs $(100.82 \pm 23.94$ minutes, $P=0.035)$ and controls $(95.25 \pm 23.29$ minutes, $P=0.021)$. The percentage of gastric retention was higher in FD than in migraine. However, migraineurs did not show an obvious delayed gastric emptying or an increase of gastric retention when compared to the normal controls. The association between each dyspeptic symptom and GE parameters was not significant, but postprandial fullness and early satiety showed a tendency of delayed GE. In migraineurs, GE time did not show significant association with nausea and vomiting during interictal periods.

\section{Conclusions}

Delayed GE does not appear to be a mechanism that patients with FD and migraine have in common. Migraineurs without dyspepsia during interictal period had normal GE, and further study for association with FD should be investigated.

(J Neurogastroenterol Motil 2012;18:412-418)

\section{Key Words}

Dyspepsia; Migraine disorders; Gastric emptying; Radionuclide imaging

Received: August 7, 2012 Revised: September 13, 2012 Accepted: September 17, 2012

(c) This is an Open Access article distributed under the terms of the Creative Commons Attribution Non-Commercial License (http://creativecommons. org/licenses/by-nc/3.0) which permits unrestricted non-commercial use, distribution, and reproduction in any medium, provided the original work is properly cited.

*Correspondence: Yunju Jo, MD Division of Gastroenterology, Department of Internal Medicine, Eulji University School of Medicine, Eulji General Hospital, 280-1, Hagye-dong, Nowon-gu, Seoul 139-711, Korea

Financial support: None.

Tel: +82-2-970-8209, Fax: +82-2-970-8621, E-mail: jyj1138@eulji.ac.kr

Conflicts of interest: None. 


\section{Introduction}

Functional dyspepsia (FD), defined as discomfort or pain in the upper part of the abdomen in the absence of organic disease but often linked to a motility disorder, occurs very commonly in the general population. ${ }^{1-3}$ Several pathophysiologic mechanisms, such as gastric acid secretion, gastroduodenal motility, Helicobacter pylori infection, psychosocial factors, and stress may play a role in the pathogenesis of $\mathrm{FD}^{4-15}$ Among them, delayed gastric emptying (GE) is traditionally considered a major pathophysiologic mechanism in $\mathrm{FD}$, and delayed $\mathrm{GE}$ has been identified in 29\%-59\% of patients with FD. ${ }^{4-15}$ Although several methods have been used for evaluating gastroduodenal motility, gastric scintigraphy has been known as the gold standard for measuring GE since it is noninvasive, reproducible, simple to perform, accurate and quantitative. ${ }^{16,17}$

In clinical practice, migraine and symptoms of upper gastrointestinal distress are among the most frequent complaints seen by clinicians. Also, dyspeptic symptoms are often seen to be accompanied by migraines. In fact, a survey on irritable bowel syndrome showed that headache was present in more than $30 \%$ of patients suffering from this condition. ${ }^{18}$ In another previous study that used the Bowel Disease Questionnaire to compare the upper abdominal symptoms in 99 patients with migraine and 488 apparently healthy subjects without migraine, $60 \%$ of the migraine patients reported frequent dyspepsia while $23 \%$ of the subjects without migraine reported dyspepsia. ${ }^{19}$ Although FD and migraine were often co-occurred among the general population, the pathophysiological link between the 2 conditions remains unclear.

Some of the patients with migraines have been associated with gastric stasis, such as FD. Recently, a study utilizing gastric scintigraphy reported that migraine patients had an abnormal gastric transit time compared to controls. ${ }^{20}$ In addition, migraine patients during the interictal period, had delayed gastric stasis compared with during the ictal period. ${ }^{21}$ However, previous studies had the limitation of not evaluating gastrointestinal symptoms during the interictal period and thus showed controversial results. ${ }^{20-22}$ Therefore, in our study we enrolled subjects with migraine without gastrointestinal symptoms during the interictal period in order to eliminate the group that overlaps with FD.

We investigated whether delayed GE plays a pathogenic role in FD patients or migraineurs without any gastrointestinal symptoms during the interictal periods. We also examined whether several parameters of GE time were associated with dyspeptic symptoms in those patients.

\section{Materials and Methods}

\section{Study Subjects}

Twenty-seven migraine patients between 18 to 50 years old were included from November 2008 to May 2010. Diagnosis of migraine was made according to the International Headache Society criteria for episodic migraine, and we excluded patients with any dyspeptic symptoms (epigastric pain, epigastric discomfort, postprandial fullness, early satiety, nausea, vomiting and abdominal bloating etc) during the interictal period. Chronic migraine patients were also excluded. Patients were excluded if they had been using daily centrally acting medications, were allergic to eggs, or had any condition known to effect gastric motility, ie, diabetes, thyroid disease, gastric surgery, anorexia, psychiatric disorders or head injury. The migraine patients underwent gastric emptying scintigraphy to measure gastric emptying time during the interictal period.

We included 12 healthy controls without other underlying disease, concurrent medication, or a clinical history of dyspeptic symptoms (epigastric pain, epigastric discomfort, postprandial fullness, early satiety, nausea, vomiting and abdominal bloating etc) and performed gastric scintigraphy. Sample size of patients with migraine and control group were calculated using Gpower sample size calculation program.

Of the patients who visited the Division of Gastroenterology of Eulji Hospital from 2004 to 2010, those who underwent gastric emptying scintigraphy were enrolled. Thirty-two FD patients were included in the study, who were selected to match the age and gender of the migraine and control groups.

Those with other organic diseases (diagnosed on upper endoscopy) were excluded. The FD patients were invited to complete the Rome II dyspepsia module questionnaire. The symptoms assessed by questionnaire included postprandial fullness, early satiety, epigastric pain, nausea and vomiting. All the subjects underwent gastric scintigraphy.

All of the FD patients, migraine patients and normal controls underwent gastroscopy and so we excluded patients with any organic diseases to induce symptoms, such as peptic ulcer, gastroesophageal reflux disease and malignancy.

This study was approved by the Ethics Committee of Eulji University School of Medicine. 


\section{Gastric Emptying Scintigraphy}

GE scintigraphy was performed in the morning after an overnight fast. Patients had to stop smoking and drinking alcohol at least 24 hours before the study. Drugs known to affect gastrointestinal motility were discontinued at least 48 hours before the study.

A test meal $(282 \mathrm{kcal})$ consisting of a ${ }^{99 \mathrm{M}}$ technetium sulphur colloid (500 $\mu \mathrm{Ci}$ )-labeled scrambled egg sandwich (2 eggs with 2 pieces of white toast) and $300 \mathrm{~mL}$ of water was employed. All subjects were obtained in the anterior and posterior projection immediately, and at 30, 60, 90 and 120 minutes after meal ingestion while the patient was standing. Scintigraphic images were obtained with a large field of view of the gamma camera using a low energy all-purpose collimator with a $20 \%$ energy window setting centered at $140 \mathrm{keV}$. Patients were allowed to sit in a chair between the standing image acquisitions.

GE was graded according to gastric half-emptying times $\left(\mathrm{T}_{1 / 2}\right)$ : normal ( $<70$ minutes), mildly delayed (70-100 minutes) and delayed ( $>100$ minutes). ${ }^{17}$ The GE parameters used were gastric $T_{1 / 2}$ and percentage of radioactive material remaining in the stomach (\% RMR) at $0,30,60,90$ and 120 minutes.

\section{Statistical Methods}

The data in the groups are expressed as mean values \pm SD. FD and migraine, FD and controls or migraine and controls were compared using the Student's $t$ test. Categorical variables were compared using the Chi-squared test. In FD, an association between dyspeptic symptoms and GE parameters were analyzed using ANOVA. In migraineurs, an association between dyspeptic symptoms and GE parameters were analyzed using Student's $t$ test.

Data were analyzed using SPSS software (version 17.0; SPSS Inc., Chicago, IL, USA). Differences were judged as statistically significant if the $P$-value was less than 0.05 .

\section{Results}

\section{Patient Characteristics}

We enrolled 27 migraine patients without any gastrointestinal symptoms during the interictal period, $32 \mathrm{FD}$ patients diagnosed by Rome II criteria, and 12 healthy people as controls. The mean migraine period was 9.25 ( \pm 7.02 ) years. Among 32 FD patients, 12 patients $(36.4 \%)$ reported postprandial fullness; 15 patients $(45.5 \%)$ early satiety; 5 patients (15.2\%) epigatric
Table 1. Baseline Characteristics of the Enrolled Patients

\begin{tabular}{lcccc}
\hline & FD & Migraine & Controls & $P$-value \\
\hline Sex $(\mathrm{M}: \mathrm{F})$ & $9: 23$ & $9: 18$ & $5: 7$ & 0.345 \\
Age $($ mean $\pm \mathrm{SD}$, yr) & $31.8 \pm 7.8$ & $31.7 \pm 8.1$ & $31.5 \pm 5.9$ & 0.760 \\
\hline
\end{tabular}

$\mathrm{FD}$, functional dyspepsia.

pain, and 5 patients $(15.2 \%)$ nausea or vomiting. When classifying them into subgroups according to the Rome II criteria, 15.2 $\%$ had ulcer-like type and $82.9 \%$ had dysmotility-like type.

Table 1 shows the patients' characteristics. The mean age and sex of the patients with FD, migraine and controls were not significantly different. The proportion of females with FD and migraine was larger than that of the control group, and FD and migraine did not show significant difference.

\section{Gastric Emptying Times}

Age-adjusted gastric $T_{1 / 2}$ are shown in Figure 1. FD patients (125.51 \pm 52.55 minutes) showed more delayed gastric $\mathrm{T}_{1 / 2}$ compared with migraine patients $(100.82 \pm 23.94$ minutes, $P=0.035)$ or controls $(95.23 \pm 23.29$ minutes, $P$ $=0.021)$. However, gastric $T_{1 / 2}$ in migraine patients showed no significant difference compared with that in the controls $(P=0.501)$.

The proportions of FD, migraine and control groups according to grade of delayed GE are shown in Figure 2. The proportion of patients with mildly delayed GE time was $24.1 \%$ in the FD group, $29.6 \%$ in the migraine group and $25.0 \%$ in the controls, and that with delayed GE time was $58.6 \%$ in the FD group, $48.1 \%$ in the migraine group and $33.3 \%$ in the controls. However, the differences in the proportions among the three groups were not statistically significant $(P=0.363)$.

\section{Percentage of Radioactive Material Remain- ing in the Stomach}

The mean gastric retention over time is shown in Figure 3. FD group showed no significant difference in the early phase compared to migraine group, yet significant gastric stasis was noted at 90 and 120 minutes $(61.21 \% \pm 13.90 \%$ vs $53.63 \% \pm$ $12.92 \%, P=0.049$ at 90 minutes respectively; $47.15 \% \pm$ $17.32 \%$ vs $38.05 \% \pm 14.63 \%, P=0.045$ at 120 minutes respectively). In addition, FD group showed gastric stasis in the delayed phase compared to controls although it was not statistically significant $(61.21 \% \pm 13.90 \%$ vs $53.28 \% \pm 11.50 \%, P=$ $0.097 ; 47.15 \% \pm 17.32 \%$ vs $38.05 \% \pm 14.63 \%, P=0.086)$. On 
A

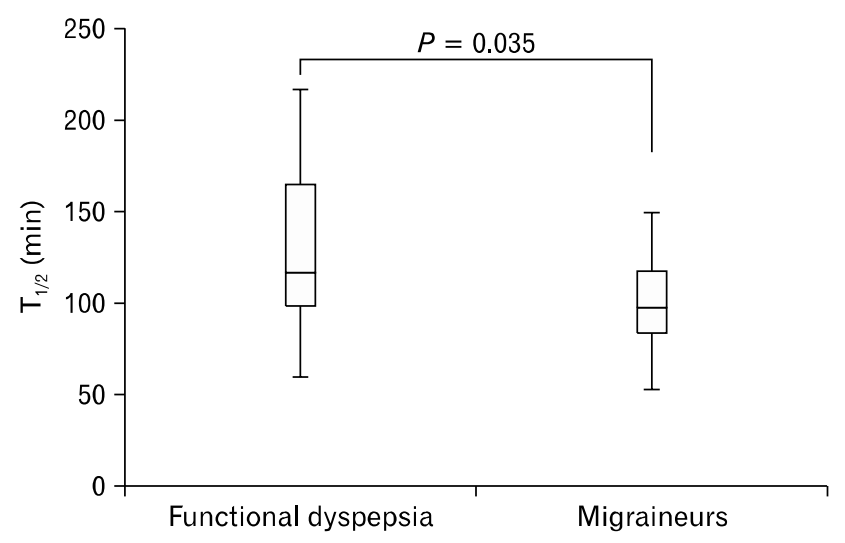

C
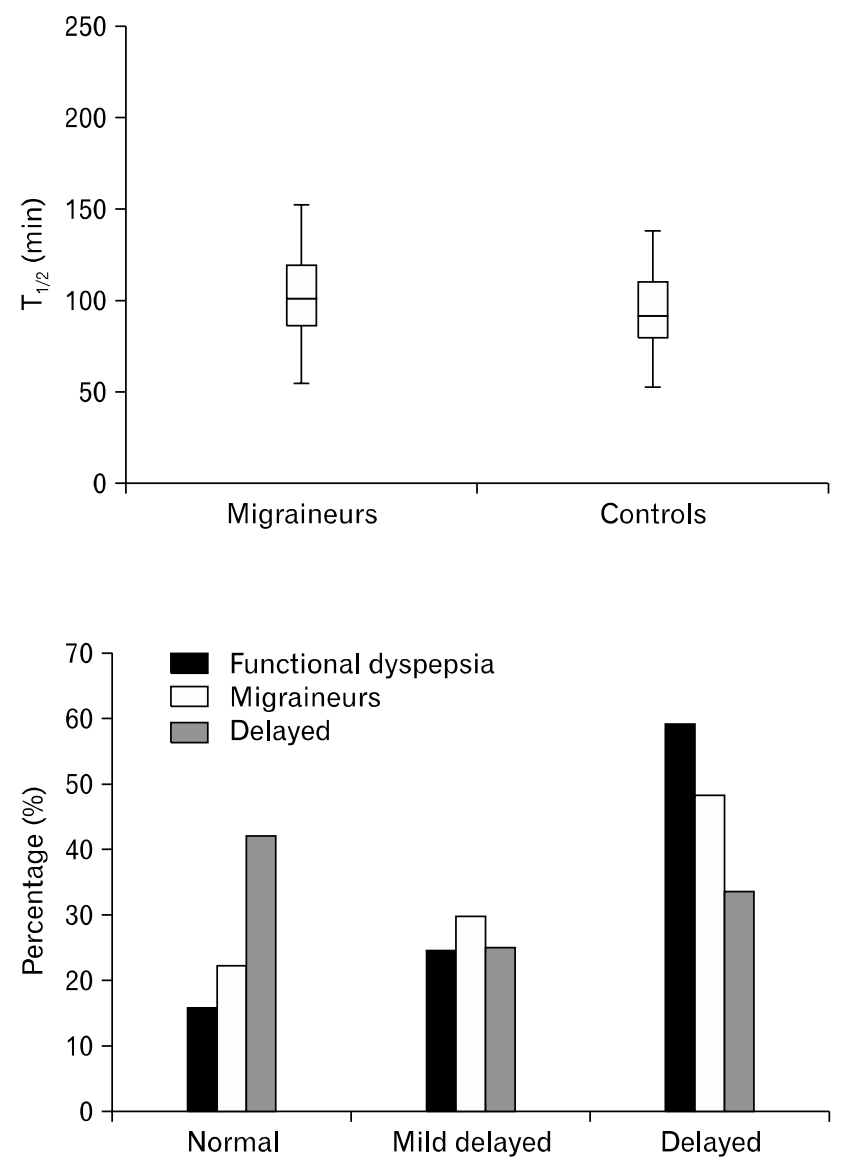

Figure 2. Proportion of the patients with functional dyspepsia (FD), migraine and controls according to grade of delayed gastric emptying. The proportion of patients with mildly delayed gastric emptying time was $24.1 \%$ in $\mathrm{FD}, 29.6 \%$ in migraineurs and $25.0 \%$ in controls, and that of delayed gastric emptying time was $58.6 \%$ in $\mathrm{FD}, 48.1 \%$ in migraineurs, and $33.3 \%$ in controls $(P=0.363)$.

\section{B}

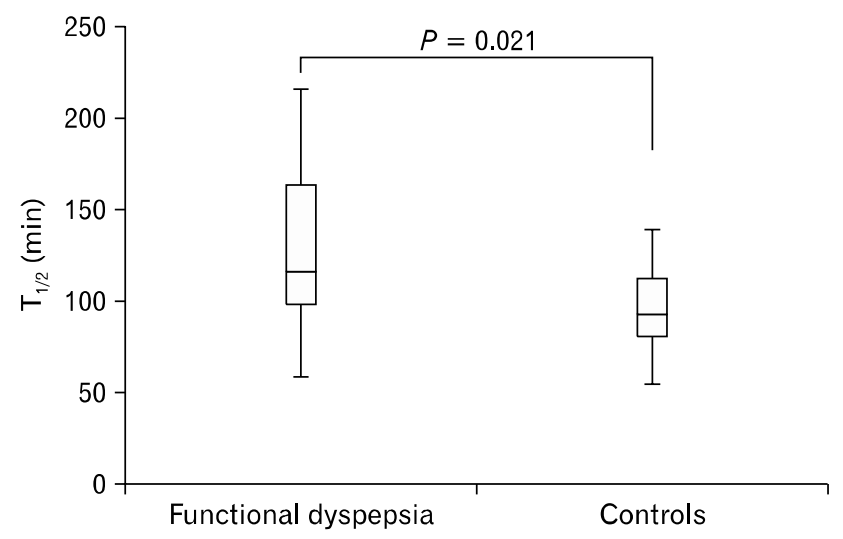

Figure 1. Age-adjusted gastric half-emptying time $\left(\mathrm{T}_{1 / 2}\right)$ in patients with functional dyspepsia (FD) compared with migraineurs and controls. The range, median, and 25th-75th percentiles are represented by error bars, bold line and box, respectively. Gastric $T_{1 / 2}$ was $125.51 \pm 52.55$ minutes in $\mathrm{FD}$ patients, $100.8 \pm 23.9$ minutes in migraineurs and $95.2 \pm 23.2$ minutes in controls (A: FD vs migraineurs, $P=0.035$; $\mathrm{B}$ : FD vs controls, $P=0.021$ ). (C) However, it did not differ significantly between the migraineurs and controls.

the other hand, migraineurs did not show a significant difference from controls.

\section{Association Between Gastrointestinal Symp- toms and Gastric Emptying Parameters}

In patients with $\mathrm{FD}$, an association was identified between dyspeptic symptoms and GE parameters, as shown in Table 2. Each GE parameter in accordance with dyspeptic symptoms did not show statistically significant differences, yet in the FD group with postprandial fullness and early satiety, GE time was more sluggish than patients with epigastric pain $(P=0.052)$. In particular, this tendency was observed significantly in gastric $T_{1 / 2}$.

Among the symptoms complained of during ictal period in migraineurs, nausea or vomiting did not show a significant difference in GE parameters (Table 3).

\section{Discussion}

We investigated whether delayed GE may play a pathogenic 
A

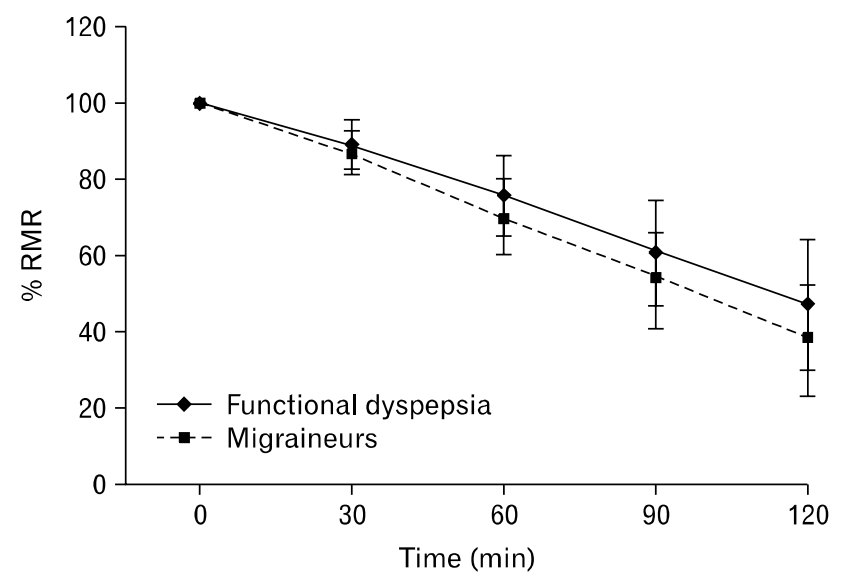

C

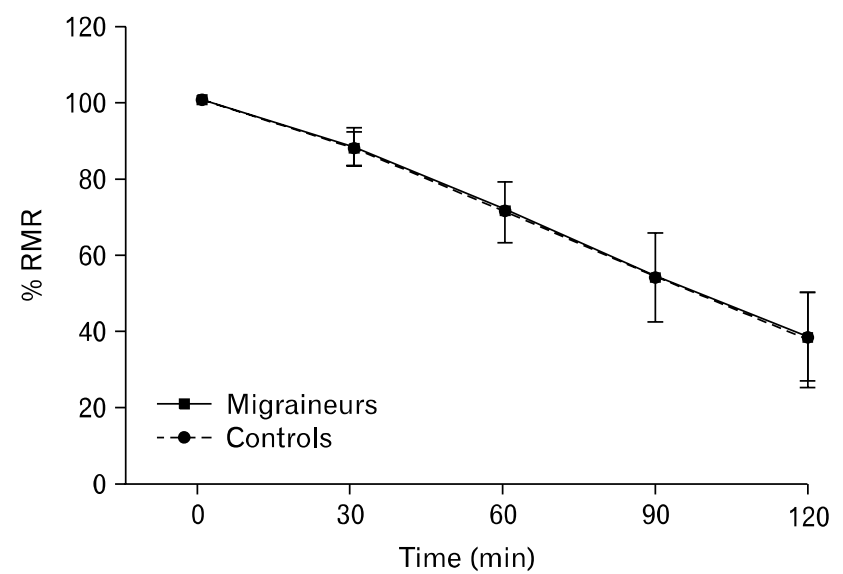

B

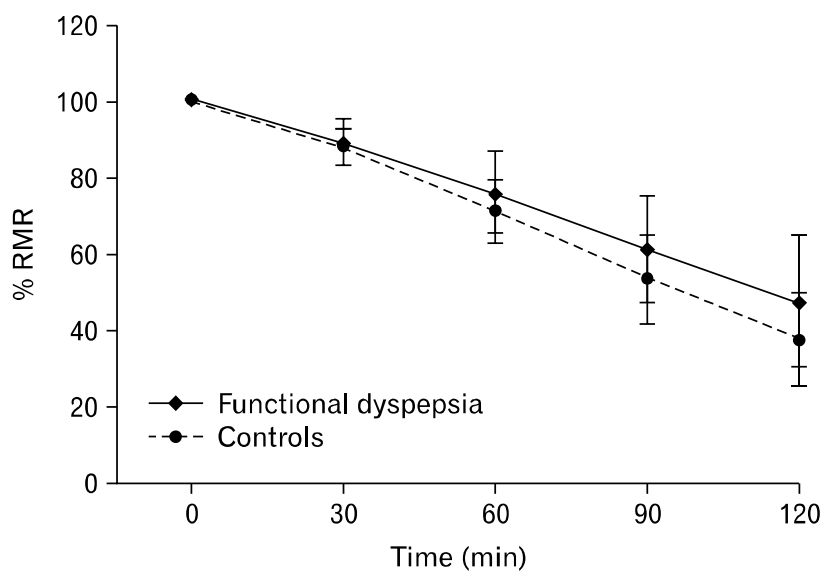

Figure 3. Age-adjusted mean gastric retention with passing time (\% RMR) in patients with functional dyspepsia (FD), migraine and controls. (A) FD group showed significant gastric stasis in 90 and 120 minutes $(61.21 \% \pm 13.90 \%$ vs $53.63 \% \pm$ $12.92 \%, P=0.049 ; 47.15 \% \pm 17.32 \%$ vs $38.05 \% \pm 14.63 \%, P$ $=0.045)$. (B) Although it is not significant, FD group showed gastric stasis compared to controls. (C) Migraineurs did not show a significant difference from controls. \% RMR, percentage of radioactive material remaining.

Table 2. Association Between Main Dyspeptic Symptoms and Gastric Emptying Parameters in Functional Dyspepsia Group ( $\mathrm{n}=32$ )

\begin{tabular}{lcccc}
\hline & Postprandial fullness $(\mathrm{n}=12)$ & Early satiety $(\mathrm{n}=15)$ & Epigastric pain $(\mathrm{n}=5)$ & $P$-value \\
\hline $\mathrm{T}_{1 / 2}$ (mean $\pm \mathrm{SD}$, min) & $125.07 \pm 34.09$ & $127.16 \pm 34.09$ & $98.41 \pm 2.58$ & 0.052 \\
30 min \% RMR & $90.67 \pm 6.41$ & $89.91 \pm 6.73$ & $84.96 \pm 7.07$ & 0.372 \\
60 min \% RMR & $77.98 \pm 11.08$ & $77.62 \pm 10.17$ & $68.88 \pm 7.38$ & 0.211 \\
90 min \% RMR & $63.03 \pm 13.77$ & $63.79 \pm 11.3$ & $53.74 \pm 5.90$ & 0.111 \\
120 min \% RMR & $48.15 \pm 17.66$ & $49.95 \pm 14.27$ & $40.58 \pm 6.62$ & 0.096 \\
\hline
\end{tabular}

$\mathrm{T}_{1 / 2}$, half-emptying time; \% RMR, percentage of radioactive material remaining.

Table 3. Association Between Nausea and Vomiting During the Ictal Period and Gastric Emptying in Migraineurs $(\mathrm{n}=27)$

\begin{tabular}{|c|c|c|c|c|c|c|c|c|c|c|}
\hline & $\mathrm{T}_{1 / 2}(\min )$ & $P$-value & $\begin{array}{c}30 \mathrm{~min} \\
\% \mathrm{RMR}\end{array}$ & $P$-value & $\begin{array}{c}60 \mathrm{~min} \\
\% \mathrm{RMR}\end{array}$ & $P$-value & $\begin{array}{c}90 \text { min } \\
\% \text { RMR }\end{array}$ & $P$-value & $\begin{array}{l}120 \mathrm{~min} \\
\% \mathrm{RMR}\end{array}$ & $P$-value \\
\hline \multicolumn{11}{|c|}{ Vomiting $($ mean $\pm \mathrm{SD})$} \\
\hline With $(\mathrm{n}=13)$ & $98.1 \pm 22.8$ & 0.280 & $87.6 \pm 4.6$ & 0.507 & $69.9 \pm 8.0$ & 0.135 & $51.0 \pm 12.8$ & 0.154 & $35.0 \pm 14.5$ & 0.162 \\
\hline Without $(\mathrm{n}=14)$ & $103.5 \pm 24.7$ & & $87.4 \pm 6.5$ & & $71.3 \pm 10.9$ & & $55.6 \pm 12.9$ & & $40.8 \pm 13.4$ & \\
\hline \multicolumn{11}{|l|}{ Nausea (mean \pm SD) } \\
\hline With $(\mathrm{n}=7)$ & $103.8 \pm 22.1$ & 0.819 & $88.3 \pm 4.5$ & 0.387 & $72.3 \pm 8.0$ & 0.295 & $55.1 \pm 11.7$ & 0.533 & $39.7 \pm 13.1$ & 0.656 \\
\hline Without $(\mathrm{n}=20)$ & $95.0 \pm 29.9$ & & $84.5 \pm 9.0$ & & $65.0 \pm 14.3$ & & $51.0 \pm 16.8$ & & $36.5 \pm 16.3$ & \\
\hline
\end{tabular}

$\%$ RMR, percentage of radioactive material remaining. 
role in the generation of gastrointestinal symptoms in patients with FD and migraine, and investigated whether several parameters of GE may be associated with dyspeptic symptoms in the patients with FD or migraine. This study showed that patients with FD had significantly more delayed GE than the migraineurs and controls. This finding may support the previous studies in which the delayed GE was considered as a major pathophysiologic mechanism in FD. ${ }^{4-15}$ In particular, gastric stasis appeared to be more significant in the delayed phase than in the early phase. On the other hand, there was no significant difference in GE between migraine patients and controls. This finding may be contrary to the results of prior studies in which the patients in the migraine groups showed delayed GE. ${ }^{12,13,19-21}$ We believe this result was caused by our selection of subjects. Migraine patients frequently complain of dyspeptic symptoms during interictal periods. ${ }^{23}$ Previous studies ${ }^{12,13,19,20}$ did not assess gastrointestinal symptoms during the interictal period. Therefore, in our study, we excluded migraine patients who had dyspeptic symptoms during the interictal periods, lowering the possibility of intermingling FD within migraine compared to the previous studies. In fact, some studies showed GE similar to the control in migraineurs during the interictal period. $^{22}$

In our study, the group complaining of postprandial fullness and early satiety showed relatively delayed GE. A recent study on breath test reported that early satiety was the only symptom associated with delayed GE. ${ }^{24}$ Postprandial fullness or vomiting is regarded as one of the dysmotility symptoms. Sarnelli et $\mathrm{al}^{5}$ studied the relationship between delayed GE and the presence or severity of individual symptoms in dyspeptic patients, using an eight-item questionnaire to assess symptom severity and breath test technology to assess GE. Delayed GE was associated with postprandial fullness and vomiting, regardless of their severity. Despite the weakness in comparing the symptoms that patients complained of, by simply dividing the symptoms into postprandial fullness, early satiety, and epigastric pain, this study demonstrated the delayed GE time in postprandial fullness and early satiety, the symptoms regarded as dysmotility symptoms by clinicians. This study examined whether the GE was associated with vomiting or nausea that occurred during the ictal period in migraine patients. However, there was no significant association between nausea, vomiting and GE in migraine group, which indicates that GE is likely to have less effect on these symptoms.

This study has some limitations. Our data lacked information about factors regarded as affecting GE, such as height, weight and body mass index except age and sex. If we had many more subjects with FD, we might have been able to obtain more reliable information on the association between dyspeptic symptoms and GE parameters. Second, in our study, the mean gastric $T_{1 / 2}$ of controls was prolonged, as compared with that in the previous data. ${ }^{17}$ This might be because there was relatively large proportion of young and female subjects enrolled. In fact, the volume and content of ingested food, mental status, age and physical exercise are known associated factors that alter GE. ${ }^{25-31}$ Therefore, we tried to obtain our own data on GE times in our hospital, because we thought it was important to collect unique data using GE scintigraphy in an individual hospital. Third, we captured just the main or most discomforting symptoms because we chose FD patients among the patients who had undergone GE scintigraphy in a single hospital. Therefore, the lack of objective symptomatic analysis was also a limitation of this study. Lastly, this study has the limitation of a single-center study targeting a small number of patients. There was also a small number of FD patients in this study because FD patients were selected to match the gender and age of the migraine and control group from the subjects who had undergone GE scintigraphy although the migraine and normal control groups were collected prospectively to conduct gastric scintigraphy during the interictal period. Therefore, further studies targeting more patients would be needed.

In conclusion, using gastric scintigraphy, this study demonstrated that GE in FD was more delayed than in migraineurs. In particular, we designed the study to exclude anyone who had experienced gastrointestinal symptoms during the interictal period from the migraine groups, thereby eliminating the overlap between migraine and FD. Therefore, this study produced different results from previous studies. ${ }^{12,13,19-21}$ In other words, it could be suggested that unlike FD, the migraine without dyspeptic symptoms does not affect GE during interictal period; nausea and vomiting complained during ictal period could be affected by another mechanism rather than delayed GE.

\section{References}

1. Agréus L, Svärdsudd K, Nyrén O, Tibblin G. Irritable bowel syndrome and dyspepsia in the general population: overlap and lack of stability over time. Gastroenterology 1995;109:671-680.

2. Lieberman D, Fennerty MB, Morris CD, Holub J, Eisen G, Sonnenberg A. Endoscopic evaluation of patients with dyspepsia: results from the national endoscopic data repository. Gastroenterology 2004;127:1067-1075.

3. Ryu KH, Kim YH, Son HJ, et al. [Various causes of dyspepsia: to determine organic and functional cause of dyspepsia.] Korean J Gastrointest Motil 1998;4:112-117. [Korean] 
4. Stanghellini V, Tosetti C, Paternico A, et al. Risk indicators of delayed gastric emptying of solids in patients with functional dyspepsia. Gastroenterology 1996;110:1036-1042.

5. Sarnelli G, Caenepeel P, Geypens B, Janssens J, Tack J. Symptoms associated with impaired gastric emptying of solids and liquids in functional dyspepsia. Am J Gastroenterol 2003;98:783-788.

6. Wegener M, Börsch G, Schaffstein J, Reuter C, Leverkus F. Frequency of idiopathic gastric stasis and intestinal transit disorders in essential dyspepsia. J Clin Gastroenterol 1989;11:163-168.

7. Jian R, Ducrot F, Ruskone A, et al. Symptomatic, radionuclide and therapeutic assessment of chronic idiopathic dyspepsia. A double-blind placebo-controlled evaluation of cisapride. Dig Dis Sci 1989;34:657-664.

8. Talley NJ, Shuter B, McCrudden G, Jones M, Hoschl R, Piper DW. Lack of association between gastric emptying of solids and symptoms in nonulcer dyspepsia. J Clin Gastroenterol 1989;11:625630.

9. Waldron B, Cullen PT, Kumar R, et al. Evidence for hypomotility in non-ulcer dyspepsia: a prospective multifactorial study. Gut 1991;32: 246-251.

10. Klauser AG, Voderholzer WA, Knesewitsch PA, Schindlbeck NE, Müller-Lissner SA. What is behind dyspepsia? Dig Dis Sci 1993;38: 147-154.

11. Scott AM, Kellow JE, Shuter B, et al. Intragastric distribution and gastric emptying of solids and liquids in functional dyspepsia. Lack of influence of symptom subgroups and $H$. pylori-associated gastritis. Dig Dis Sci 1993;38:2247-2254.

12. Quartero AO, de Wit NJ, Lodder AC, Numans ME, Smout AJ, Hoes AW. Disturbed solid-phase gastric emptying in functional dyspepsia: a meta-analysis. Dig Dis Sci 1998;43:2028-2033.

13. Maes BD, Ghoos YF, Hiele MI, Rutgeerts PJ. Gastric emptying rate of solids in patients with nonulcer dyspepsia. Dig Dis Sci 1997;42:1158-1162.

14. Perri F, Clemente R, Festa V, et al. Patterns of symptoms in functional dyspepsia: role of Helicobacter pylori infection and delayed gastric emptying. Am J Gastroenterol 1998;93:2082-2088.

15. Talley NJ, Verlinden M, Jones M. Can symptoms discriminate among those with delayed or normal gastric emptying in dysmotility-like dyspepsia? Am J Gastroenterol 2001;96:1422-1428.

16. Seok JW. How to interpret gastric emptying scintigraphy. J Neurogastroenterol Motil 2011;17:189-191.

17. Abell TL, Camilleri M, Donohoe K, et al. Consensus recommendations for gastric emptying scintigraphy: a joint report of the American Neurogastroenterology and Motility Society and the
Society of Nuclear Medicine. J Nucl Med Technol 2008;36:44-54.

18. Whorwell PJ, McCallum M, Creed FH, Roberts CT. Non-colonic features of irritable bowel syndrome. Gut 1986;27:37-40.

19. Kurth T, Holtmann G, Neufang-Huber J, Gerken G, Diener HC. Prevalence of unexplained upper abdominal symptoms in patients with migraine. Cephalalgia 2006;26:506-510.

20. Aurora S, Kori S, Barrodale P, Nelsen A, McDonald S. Gastric stasis occurs in spontaneous, visually induced, and interictal migraine. Headache 2007;47:1443-1446.

21. Aurora SK, Kori SH, Barrodale P, McDonald SA, Haseley D. Gastric stasis in migraine: more than just a paroxysmal abnormality during a migraine attack. Headache 2006;46:57-63.

22. Yalcin H, Okuyucu EE, Ucar E, Duman T, Yilmazer S. Changes in liquid emptying in migraine patients: diagnosed with liquid phase gastric emptying scintigraphy. Intern Med J 2012;42:455-459.

23. Meucci G, Radaelli F, Prada A, et al. Increased prevalence of migraine in patients with uninvestigated dyspepsia referred for openaccess upper gastrointestinal endoscopy. Endoscopy 2005;37:622625.

24. Ron Y, Sperber AD, Levine A, et al. Early satiety is the only patient-reported symptom associated with delayed gastric emptying, as assessed by breath-test. J Neurogastroenterol Motil 2011;17:61-66.

25. Heading RC, Tothill P, McLoughlin GP, Shearman DJ. Gastric emptying rate measurement in man. A double isotope scanning technique for simultaneous study of liquid and solid components of a meal. Gastroenterology 1976;71:45-50.

26. Moore JG, Christian PE, Brown JA, et al. Influence of meal weight and caloric content on gastric emptying of meals in man. Dig Dis Sci 1984;29:513-519.

27. Moore JG, Datz FL, Christian PE, Greenberg E, Alazraki N. Effect of body posture on radionuclide measurements of gastric emptying. Dig Dis Sci 1988;33:1592-1595.

28. Roland J, Dobbeleir A, Vandevivere J, Ham HR. Effect of mild mental stress on solid phase gastric emptying in healthy subjects. Nucl Med Commun 1990;11:319-326.

29. Goo RH, Moore JG, Greenberg E, Alazraki NP. Circadian variation in gastric emptying of meals in humans. Gastroenterology 1987;93:515-518.

30. Moore JG, Tweedy C, Christian PE, Datz FL. Effect of age on gastric emptying of liquid-solid meals in man. Dig Dis Sci 1983;28:340344 .

31. Moore JG, Datz FL, Christian PE. Exercise increases solid meal gastric emptying rates in men. Dig Dis Sci 1990;35:428-432. 